\title{
SCOLIOSIS IN TWINS
}

\section{G. Murdoch, Dundee, Scotland}

In pure lines comprising descendants obtained from self-fertilisation of a single homozygous parent, any variation is due to environmental factors. Because pure lines do not occur in man, twins afford the only opportunity to study the interaction of genotype and environment. Ideally the incidence of abnormalities occurring in a series of uniovular twins should be compared to that in a series of binovular twins, but this will be possible only if all such abnormalities in twins are reported.

Scoliosis secondary to anatomical spinal abnormality such as a hemivertebra has been reported in twins by Haffner (1936). Idiopathic scoliosis in identical twins has been described by Weiser (1947) and more recently by Esteve (1958) and H-Ros Codorniu (1958), with a close similarity in all three reports. In Weiser's pair, although the convexity was dissimilar, the
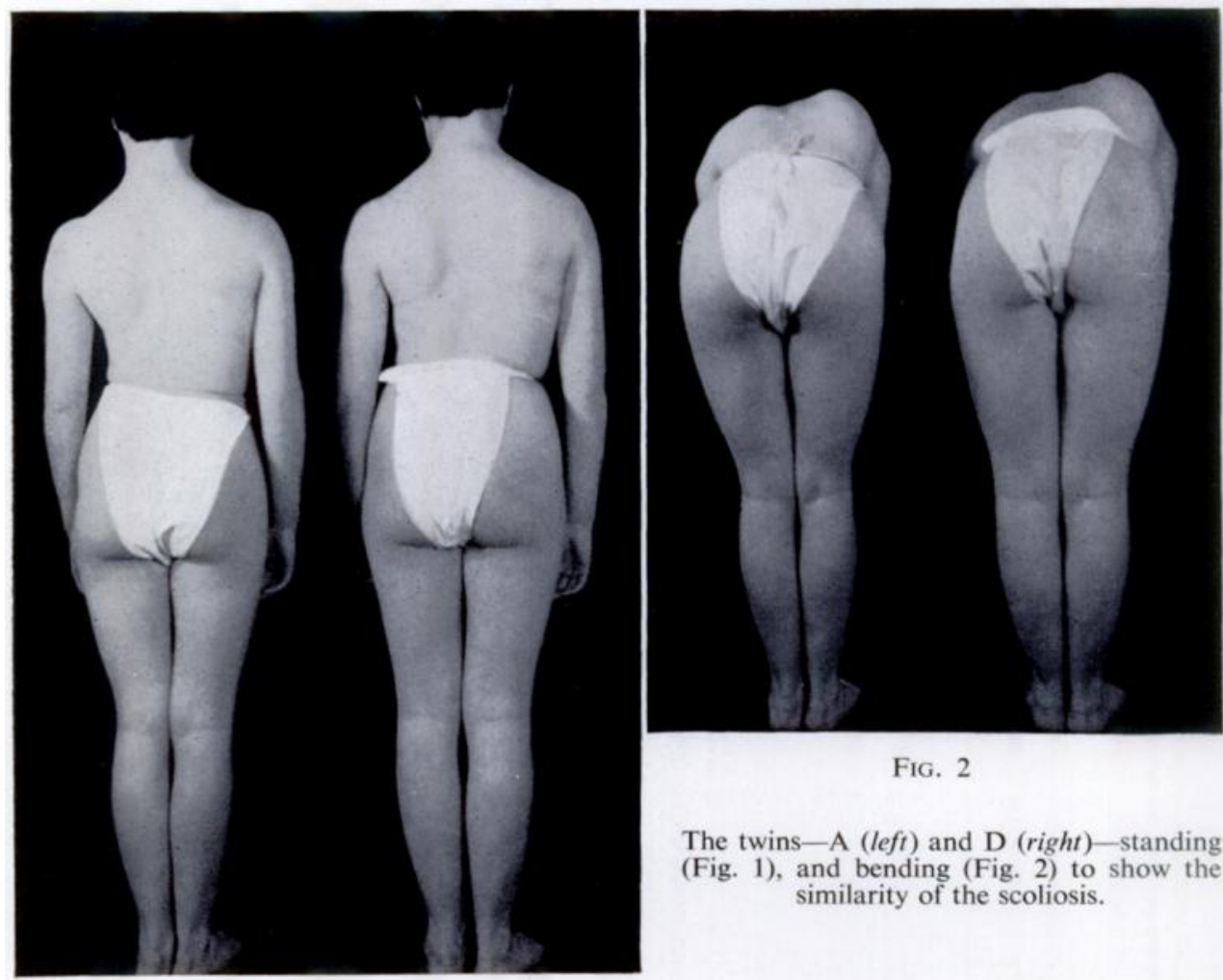

FIG. 2

The twins-A (left) and D (right) - standing (Fig. 1), and bending (Fig. 2) to show the similarity of the scoliosis.

Fig. 1

curves were of the same magnitude and situation, while in the twins of H-Ros Codorniu and Esteve the curves conformed in pattern, degree and convexity.

Another example of identical twins with a similar idiopathic scoliosis is reported here.

\section{CASE REPORT}

As in the previous reports mentioned, the twins were girls. There was no family history of scoliosis or other abnormality. There were no brothers or sisters and both parents were 
alive and well. Twin D was slightly taller and heavier than her sister $\mathrm{A}$, but in all other respects they were identical, including the colour, type and distribution of hair, the colour of eyes and skin, physical development and blood groups. This polysymptomatic similarity can be taken as proof that the twins were uniovular.

They presented at the age of sixteen. Each had a lower thoracic scoliosis, convex to the right (Figs. 1 and 2). The curves, which extended from the fifth to the eleventh thoracic vertebra in both girls, had an angulation of 46 degrees in $A$ and 55 degrees in D (Fig. 3). There was no spina bifida, hemivertebra or other spinal abnormality. In both twins growth was completed without deterioration of the scoliosis.

The scoliosis in these girls is of the idiopathic thoracic type of late onset described by Ponseti and Friedman (1950), or the adolescent variety of James (1954).

\section{DISCUSSION}

This further example of a similar idiopathic scoliosis in identical twins supports the suggestion that this condition depends on hereditary factors. The need for reporting all twins with scoliosis, including the occurrence in one or both members of a pair of binovular twins, is clear. The exact nature of this hereditary factor is not known. Kleinberg (1926) observed the altered vascular patterns in scoliosis and more recently Trueta (1958)

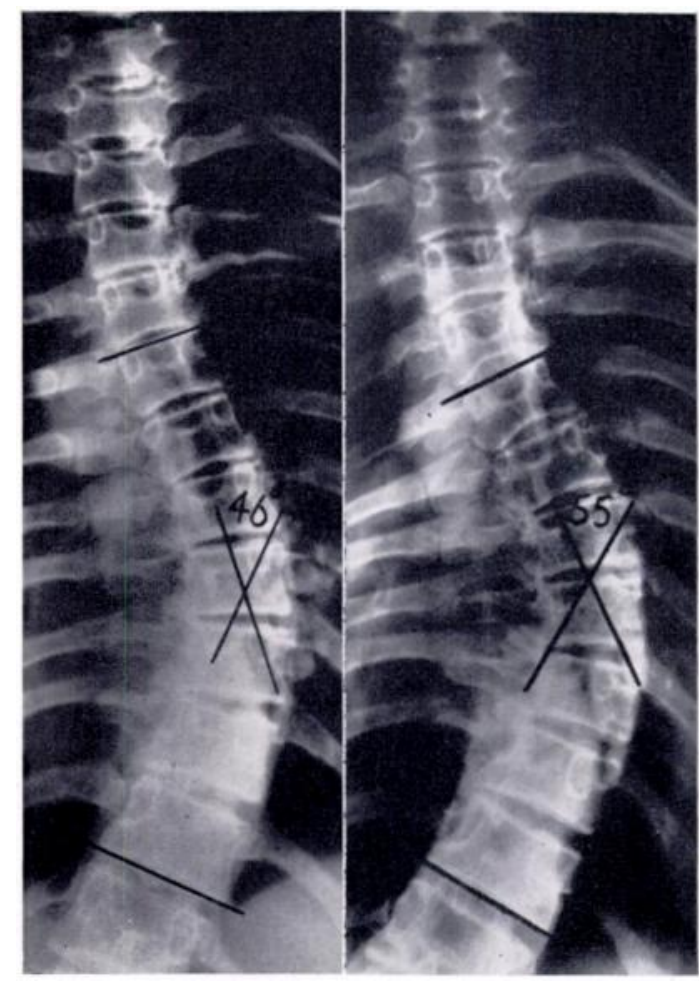

FIG. 3

Radiographs of the twins-A (left) and D (right)showing the similarity of the curves. has pointed out that disturbances of blood flow to the epiphysial plate may cause both over-activity or its transient or permanent arrest. Despite the work of Riddle and Roaf (1955) on the relationship of muscle imbalance to idiopathic scoliosis, it seems likely that Trueta's observations have a more direct bearing on any hereditary factor.

\section{REFERENCES}

Esteve, R. (1958): Idiopathic Scoliosis in Identical Twins. Journal of Bone and Joint Surgery, 40-B, 97. HAFFNER, J. (1936): Eineiige Zwillinge mit symmetrischer Wirbelsäulendeformität. Keilwirbel. Acta Radiologica, $17,529$.

H-Ros Codorniu, A. (1958): “ Idiopathic “ Scoliosis of Congenital Origin. Journal of Bone and Joint Surgery, 40-B, 94.

James, J. I. P. (1954): Idiopathic Scoliosis. Journal of Bone and Joint Surgery, 36-B, 36.

KleinberG, S. (1926): Scoliosis. New York: Paul B. Hoeber.

Ponseti, I. V., and Friedman, B. (1950): Prognosis in Idiopathic Scoliosis. Journal of Bone and Joint Surgery, 32-A, 381.

RiDile, H. F. V., and Roaf, R. (1955): Muscle Imbalance in the Causation of Scoliosis. Lancet, i, 1,245.

Trueta, J. (1958): Trauma and Bone Growth. Report of Septième Congrès International de Chirurgie Orthopédique, Barcelone, 16-21 Septembre 1957, p. 329. Bruxelles: Imprimerie des Sciences, S.A.

WeISER, M. (1947): Spiegelbildliche Skoliosen bei Zwillingen. Zeitschrift für Orthopädie, 76, 264. 